\title{
The Digital Transformation: The Qualitative Analysis of the Change Management of a Mid-Size Company
}

\author{
Marilou Kordahi \\ University of Paris 8 \\ Saint Joseph University of Beirut
}

The objective of this article is to analyze the change in organizational practices of a company faced with a competitive environment and digital variability. The research work is based on the application of Porter's five forces model and the matrix of change. Porter's Five Forces are used to determine the environment in which a company operates. The Matrix of Change allows for a structured analysis of organizational practices to anticipate the interrelationships among them. The case study concerns a mid-sized company, which has made a name for itself by driving innovation at its industrial site. This company is striving to adapt to digital variability by investing in business tasks and processes for commercial purposes.

Keywords: digital technology practices, information watch, digital transformation, qualitative analysis, mid-size companies

\section{INTRODUCTION}

In their 2003 work (p. 238), Vallabh Sambamurthy et al. explained that: "the convergence of computing, communications, and content technologies offers firms significant opportunities for enhancing agility", or their ability to quickly identify and seize market opportunities. Organizations invest in information technology and digital technologies (e.g., production automation, data warehousing) to take advantage of these functional capabilities, and ultimately improve their own competitive strategies (Hess et al., 2016; Sambamurthy et al., 2003).

We wish to contribute to the disciplines of Information and Communication Sciences and Management Sciences by focusing on the impact of information and digital technologies on organizations' strategies. We address the topic of "digital transformation" and its ability to influence the competitive strategy of organizations (Vial, 2019; Hess et al., 2016; Kane et al., 2015; Fitzgerald et al., 2014; Westerman et al., 2011). Westerman et al. (2011) defined "digital transformation" as the use of technology to further develop the performance and competitiveness of organizations. According to Hess et al. (2016) and Westerman and Bonnet (2015), "digital transformation" contributes to changes in organizational uses and practices by creating new business models in a particular area (e.g., customer relationship management).

We propose to study a case of the digital transformation of a mid-sized French company (ETI), to ultimately analyze its agility and competitive strategy. We are interested in the field of flavor and fragrance chemistry, and propose to treat the case of ETI A in France. This ETI has attracted our attention because of its commitment to the modernization of its industrial site and its growth strategy in France and internationally (ETI A, 2019, 2015). This medium-sized French company is specialized in natural raw 
materials. It has developed an approach involving the Group from the cultivation of ingredients to the processing and creation of natural products (ETI A, 2019, 2015).

The problematic is as follows: how can ETI A organize change in its organizational practices, in the face of a competitive environment and digital variability?

We propose to solve this problem in two steps. First of all, we will start by analyzing the competitive environment of ETI. It seems to us that Porter's $(2008,1980)$ five forces model is suitable for this study. It is used to conduct a structured analysis to determine the competitive environment in which a firm operates. These threats come primarily from the intensity of competition, substitutes, new entrants, and the bargaining power of suppliers and customers. The assessment of these five forces highlights the company's strategic strengths and weaknesses, taking into consideration its organizational practices. Then, we will deepen this analysis further, looking at the organizational practices involved in the ETI change. We propose to use the matrix of change of Brynjolfsson et al. (1996). It is a structured analysis to help decision-makers anticipate the complex interrelationships that surround a company's change. The matrix of change system consists of three matrices and a set of assessments. These matrices are the current practices, the desired practices and the state of transition that connects these two. The set of evaluations includes stakeholder interests, feasibility, sequence of execution location, and pace of change.

To our knowledge, there is limited published work dealing with the digital transformation of Provençal and French ETIs while using Porter's five forces and the matrix of change. However, the topics of strategy, digital transformation and change have attracted the interest of a large number of researchers. Marilou Kordahi (2019) analyzed the case of an ETI facing digital variability, using the contextualist model of change and the matrix of change. Chan Kim and Renee Mauborgne (2014), Michael Porter (2008, 1980), Henry Mintzberg (et al., 1976; 1973) have conducted extensive research on organizational strategy. Lukasz Arendt (2008) and Fillis Wagner et al. (2003) have analyzed the subject of computerization in Small and Medium Enterprises (SMEs) and the challenges encountered. Marc Peter et al. (2020), Gregory Vial (2019), Thomas Hess et al. (2016), Georges Westerman and Didier Bonnet (2015), Michael Fitzgerald et al. (2014), Georges Westerman et al. (2011) and Don Tapscott (1996) examined the digital transformation of organizations and the adaptation of their strategies to competitive environments. On the other hand, David Autissier and Jean-Michel Moutot (2016), Norbert Alter (2015), David Autissier et al. (2014), Wanda Orlikowski (2000), John Kotter (1997), Erik Brynjolfsson et al. (1997, 1996) and Nicole Giroux (1991) have studied the subjects of change and its conduct.

The article is divided into four sections. We will first explain the use of the documentary research method applied to our case study. Then, we will determine the strategic position of this ETI using Porter's five forces model. Next, we will construct and analyze the matrix of change of the family business. Finally, we will discuss all of the work developed before concluding our article.

\section{DOCUMENTARY RESEARCH}

We propose to conduct a documentary research to analyze previous information (or secondary information) around the management of the digital transformation of this ETI. On several occasions, we have tried to get in touch with company A, in order to conduct group or individual interviews and collect primary information, without success.

This research is based on two main resources: the ETI's Social Responsibility (CSR) reports (ETI A, 2019, 2015) as well as online articles published in general newspapers and a specialized journal. We mention Le Monde, Le Figaro, L'Express, Les Echos, La Tribune and L'Usine Nouvelle. L'Usine Nouvelle is a French journal specialized in economics and technology in the industrial world. These newspapers and journal are reliable sources of information.

We carried out a preparatory work whose main objective was to compare the contents of the CSR reports with those of the published articles. We checked the consistency and continuity of the published information. We did not find any inconsistencies. 


\section{THE PORTER'S FIVE FORCES ADAPTED TO THE ETI A: FIRST APPROACH}

In what follows, we will present consecutively the forces the company is facing: the competitive rivalry, threats of new entrants as well as bargaining power of suppliers and customers. We will explain the approach followed by this ETI to reduce the intensity of each force. Given the company's area of specialization, we have not found a substitute that would pose a threat to its growth.

\section{The Power of Competition}

The Group's competitors are companies specialized in the design, manufacture and commercialization of natural and synthetic flavors in the food, pharmaceutical, cosmetics, therapeutic and tobacco sectors. This ETI is essentially threatened by the market positioning of companies B and C, and by the specific specialization of company D. Companies B and C are respectively the "leaders" worldwide and in France in the manufacture and commercialization of natural and synthetic perfumes and flavorings. These companies have robotized their factories and opened international subsidiaries in order to further diversify their product lines and hold a larger market share. Company D is a major producer of natural plant-based ingredients for the agri-food, cosmetics and pharmaceutical sectors. It has developed international subsidiaries in order to expand its market share

Over the last decade, ETI A has robotized its industrial site, further diversified its production range and made acquisitions of companies in the United States and emerging countries in order to reduce the intensity of the competitive force, that of companies $\mathrm{B}$ and $\mathrm{C}$ in particular. It has also acquired Company $\mathrm{E}$, dedicated to the development of biological products, and is investing in the pharmaceutical sector (ETI A, 2019, 2015) in order to compete with Company D.

\section{The Power of New Entrants}

For this ETI, the two threats, coming from new entrants in the natural ingredients market, are the plagiarism of their innovations and the rapid growth of these entrants. For example, the innovations concern the discovery of a new natural ingredient, techniques for extracting natural raw materials (ETI A, 2019, 2015). In the 1990s, SMEs specialized in the natural ingredients industry emerged.

The ETI A set up four types of barriers to reduce the intensity of new entrants (Porter, 2008, 1980). Firstly, between 2007 and 2016, by acquiring SMEs, the ETI diversified its range of natural ingredients and protected its know-how. Secondly, this company, founded in 1850, offered to share operations and functions with its other subsidiaries so that they could benefit from its acquired experience. It has also shared the costs generated from the manufacture of common materials with its subsidiaries (ETI A, 2019, 2015). This approach has improved the reduction of material extraction, processing and manufacturing costs. Thirdly, the Group has differentiated itself from the competition of new entrants by its reputation, a luxury clientele, a wide range of products and a broad distribution network (ETI A, 2019, 2015). And, fourthly, this ETI began by filing patents to protect its innovative methods. For example, in 1994, ETI A developed products to overcome unpleasant and industrial odors. This innovation is protected by a patent.

\section{The Bargaining Power of Suppliers}

ETI A uses four types of procurement approaches: purchasing raw materials from various suppliers, partnership, joint venture and subsidiary. The procurement of raw materials from external suppliers is done in France as well as internationally (ETI A, 2019, 2015). Given that the number of companies involved in the natural ingredients industry is small and the group of suppliers is concentrated, the force that suppliers can exert on ETI A is strong and can be manifested by increasing prices and reducing the quality of the ingredients sold (Porter, 2008, 1980).

Beginning in the 1980 s, the company chose to establish subsidiaries, joint ventures, and supply partnerships in Europe, the United States, and emerging countries in order to level the bargaining power of suppliers. The initiative to have a greater variety of sourcing approaches allows the Group to control its supply chains, evaluate the quality of the raw materials extracted, discover new natural ingredients and explore new markets (ETI A, 2019, 2015).

Journal of Applied Business and Economics Vol. 22(14) 2020213 


\section{The Bargaining Power of Buyers}

The company ETI A sells its natural ingredients to major customers, specialized in perfumery and food products, in France and worldwide. ETI A's area of specialization makes the Group dependent on a particular luxury clientele. The bargaining power of buyers is therefore rather strong (Porter, 1980).

From the last three decades to the present day, this family business has been building customer loyalty by taking care of its brand image. It is also striving to conquer new market segments by further diversifying its products, in order to eventually reduce the intensity of this threat. This two-pronged approach is reflected in the opening of offices around the world, the export and sale of products in new markets (e.g., China, Singapore), the creation of new product lines and the establishment of Research and Development centers in various countries (ETI A, 2019, 2015).

\section{FIGURE 1 \\ AN OVERVIEW OF THE RESULTS OF PORTER'S FIVE FORCES OF THE FAMILY BUSINESS}

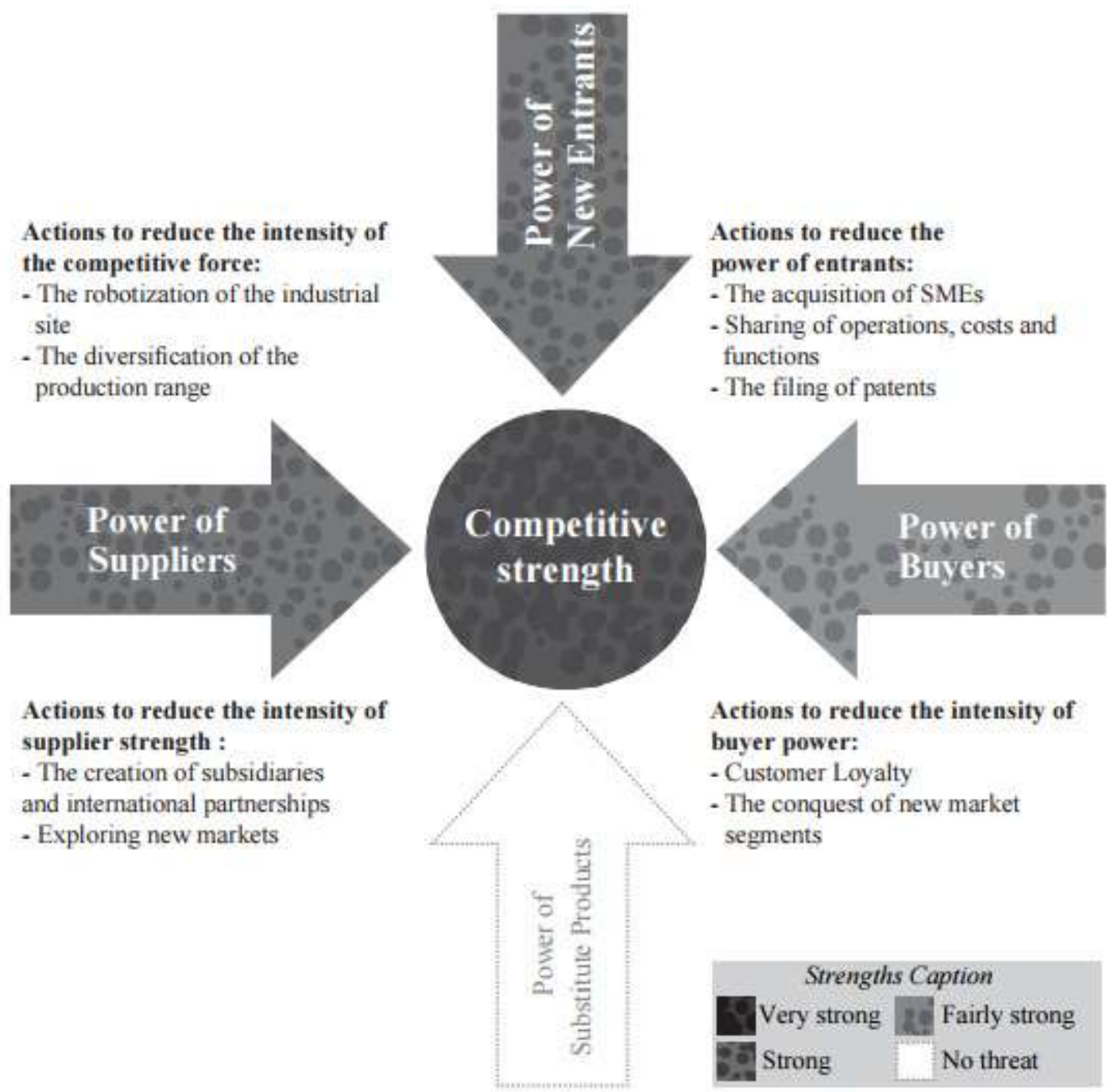

In Figure 1, we represent the key results of Porter's five forces. Following the analysis of competitive forces, we note that the company stands out from the competition through innovation, organic growth and an international focus. The organizational practices implement the decisions proposed by management. 
Moreover, change and technological progress represent a factor (and not a force) that would threaten the Group's growth over time (Autissier and Moutot, 2016; Porter, 2008; Henderson \& Venkatraman, 1993). They would initiate the creation of new substitute products, improve the performance of existing products, or even reduce the manufacturing costs of competing products (Vial, 2019; Hess et al., 2016; Fitzgerald et al., 2014; Porter, 2008; Henderson \& Venkatraman, 1993).

Since 2008, ETI A has been taking advantage of recent technological innovations (Peter el. al., 2020; Grange \& Ricoul, 2017; Autissier \& Moutot, 2016; Sambamurthy et al., 2003; Gallivan et al., 1994) by managing a program of change. Its motive is to robotize its industrial site, reduce its material processing costs and develop new product segments to respond more quickly to customer needs (ETI A, 2019, 2015; Hopkins, 2010).

In the following section, we will study organizational practices involved in the change program of this ETI. Our explanation will focus on the period between 2008 and 2025 (ETI A, 2019, 2015). We will present the method used to design the matrix of change (Brynjolfsson et al., 1997, 1996).

\section{THE FIRST APPROACH TO THE CONSTRUCTION OF THE MATRIX OF CHANGE}

This section consists of three main paragraphs. First, we will explain the approach adopted to prepare the construction of the matrix of change, applied to the two ETI sites, the head office and the industrial site. Then, we will present consecutively the construction of the matrices of current and desired practices, as well as the matrix of the state of transition of these two sites. Finally, we will analyze the resulting matrix of change, looking at its guidelines.

\section{The Presentation of the Preparatory Work}

We suggest constructing the matrix of change (Brynjolfsson et al., 1996) for the two ETI sites, using their CSR reports $(2019,2015)$ and articles published online, between 2009 and 2020.

When analyzing the extracted information, we apply three criteria. They are as follows: the year in which the data is published must be greater than or equal to 2008, the themes addressed must be related to the Group's change program, and the research must concern the Group's head office and industrial site (Kordahi, 2019). This content analysis helps us to select nearly twelve articles in a journal, newspapers and of course CSR reports. We take the liberty of citing only the names of the journal and newspapers, from which we select the articles: L'Usine Nouvelle, Le Monde, Le Figaro, La Tribune and L'Express.

Then, following the treatment of the resources indicated above, we distinguish five functions contributing to the definition and implementation of the change program. These functions are management, human resources, engineering, logistics and research and development.

Processing these same digital documents allows us to extract, code and classify the specific aspects and constituent tasks of the matrix of change (Brynjolfsson et al., 1996). We group the aspects and their corresponding tasks according to each function (Kordahi, 2019). For example, the following four aspects belong to the management function: involvement of the group's partners, international growth, development of new market segments and expansion of the Grasse sites (Figure 3).

\section{The Construction of Matrices of Current and Desired Practices}

The construction of the matrices of current and desired practices is based on the work carried out in the previous paragraph. First of all, we distinguish the specific aspects of current and desired practices at Company A. From the specific aspects defined, we identify the corresponding constituent tasks (Brynjolfsson et al., 1996). For example, in the matrix of current practices, we determine the specific aspect of implementing efficient processes to which we assign the constituent tasks to automate processes and reduce costs, lead times, and inventory. In the matrix of desired practices, we determine the specific aspect to expand the sites to which we assign component tasks create new powder blending units and produce savory flavors.

Then we build the matrices of current and desired practices, using the specific aspects and their corresponding component tasks (Figure 2). Each of the two matrices is thus composed of its specific aspects 
and constituent tasks. Each constituent task is classified according to the specific aspect on which it depends.

In each matrix, we create interactions between two constituent tasks in order to evaluate the stability of practices (Brynjolfsson et al., 1996). There are three types of interaction: a positive interaction that reinforces the practices of two tasks, a negative interaction that initiates an interference between the practices of two tasks, and no interaction that does not indicate an obvious interaction (Brynjolfsson et al., 1996). For example, in the matrix of current practices, the automation of processes reinforces the task of reducing costs, lead times and inventories and the one of developing the quality control system (Figure 2).

\section{FIGURE 2}

\section{THE REPRESENTATION OF A PART OF THE TWO MATRICES OF ETI A}
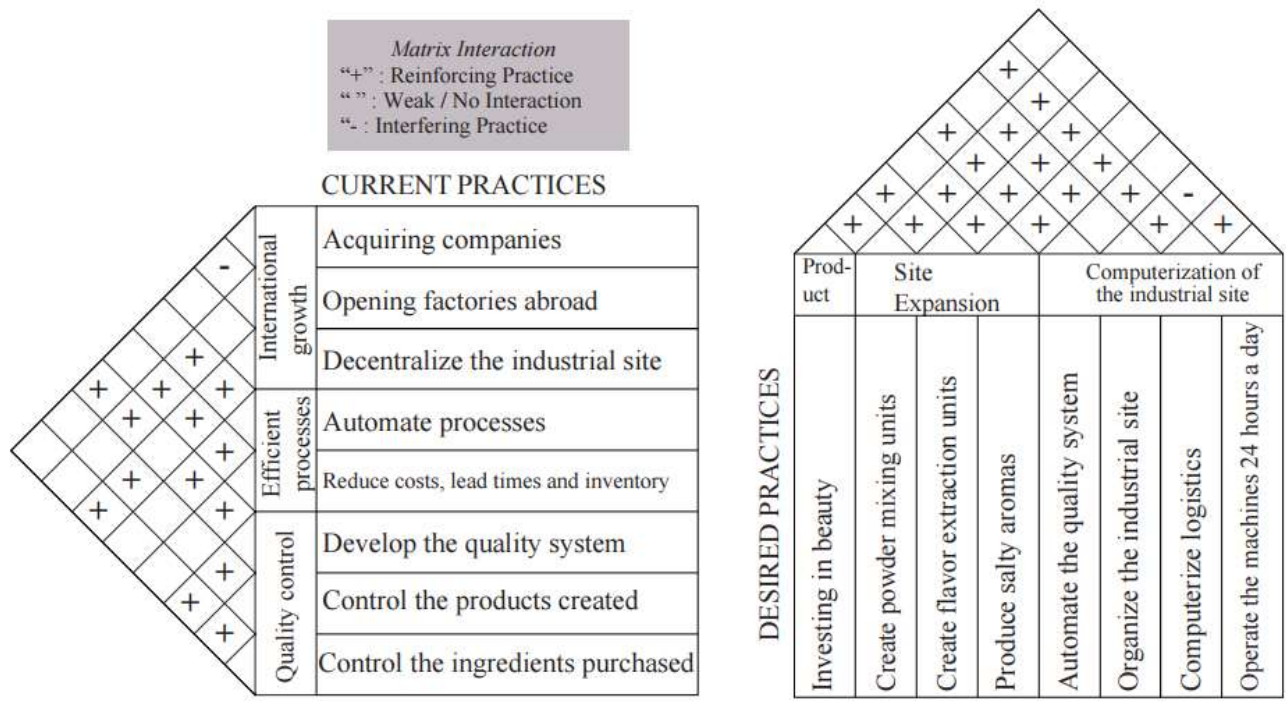

The intersection of the two matrices, current and desired practices, forms the third matrix, the transition state (Brynjolfsson et al., 1996). This matrix highlights the types of interaction between the tasks that make up current and desired practices. Here again, the types of interaction are positive, negative and nil. For example, the task of acquiring companies reinforces the task of investing in cosmetics. But it interferes with the tasks of creating powder blending and flavor extraction units, and the production of salty flavors.

Figure 2 shows a part of the two constructed matrices and the interactions between the constituent tasks of the corresponding specific aspects. Figure 3 shows a part of this matrix of change and interactions between the different constituent tasks. 


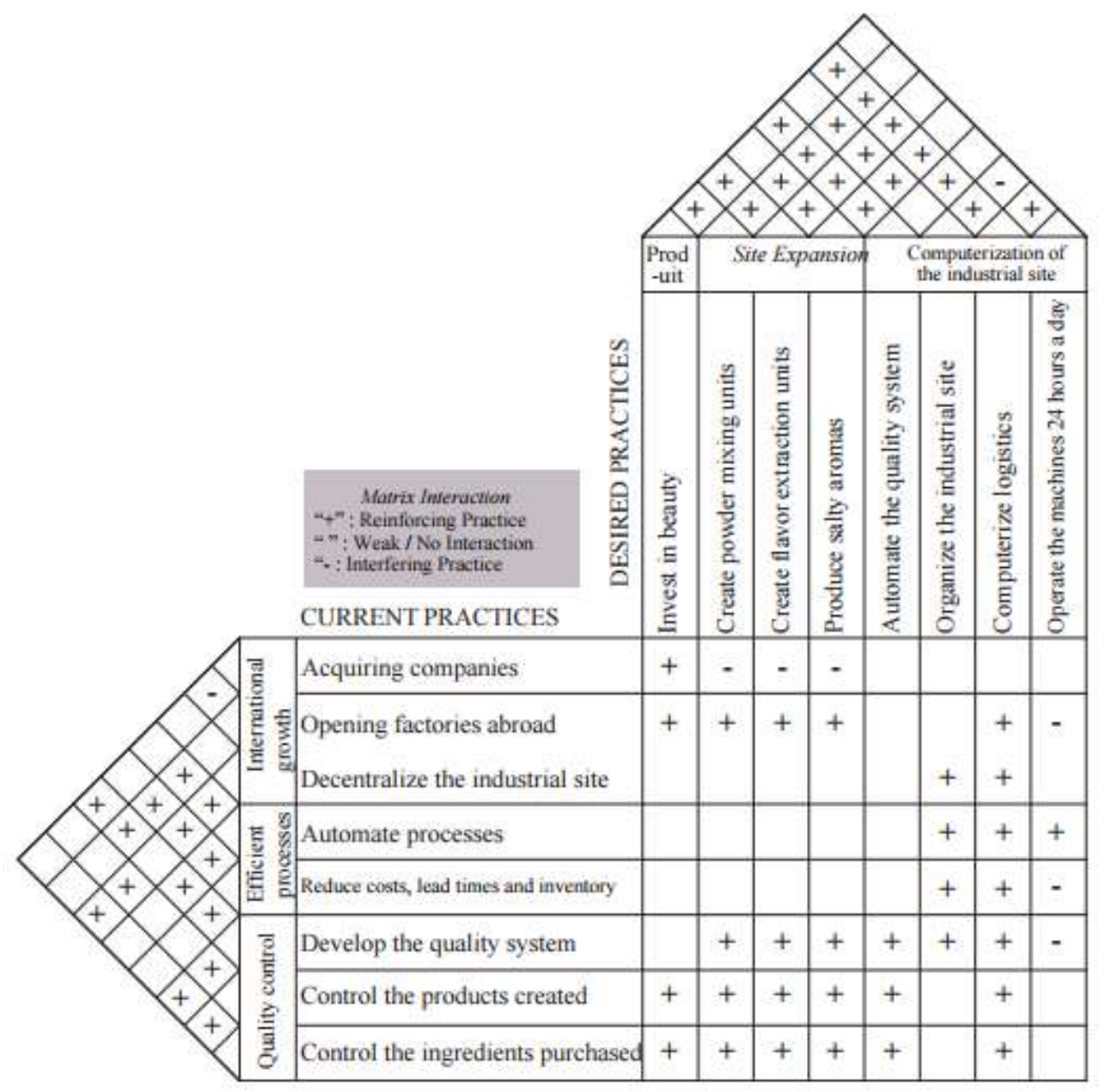

\section{Analysis of the Constructed Matrix of Change}

We study the matrix of change implemented using four guidelines: feasibility, sequence of change, location (Figure 3), and pace of change (Brynjolfsson et al., 1996).

\section{Feasibility}

The constructed matrix of change shows a major stability between specific aspects and constituent tasks, with a vision of global growth. The current practices of the system are rather stable. They have been in place for more than ten years and have therefore evolved by eliminating contradictory practices (Kordahi, 2019). The desired practices also show some stability. The state of transition is dominated by reinforced interactions that reflect a major stability. However, this state of transition shows the existence of tasks that compete with others. For example, the task of operating machines 24 hours a day interferes with the tasks of opening international factories, reducing costs, lead times and stocks, and developing the quality control system. The ETI should review these constituent tasks in order to reduce this internal interference or propose new tasks to eliminate this contradiction. 


\section{Sequence of Change}

Some tasks in the desired practices support several tasks in the current practices. For example, the task of computerizing logistics supports seven existing tasks. First, it would be pragmatic to implement the new constituent tasks that support the existing tasks. This approach would ensure a continuous link between current and desired practices and the stability of the system's processes (Simon, 1987; Mintzberg et al., 1976).

\section{The Location}

The management of this ETI made a breakthrough decision (Hess et al., 2016; Westerman and Bonnet, 2015) by choosing to decentralize the industrial site of the head office, modernize, robotize and computerize it (Kordahi, 2019). The objective of this decision would be to prepare the Group for the next conquest of new market segments on a national and international scale (ETI A, 2019, 2015).

\section{The Pace of Change}

Based on the selected resources, we recall that the change program began in 2008 and is still ongoing. The pace of change is slow (Alter, 2015; Gallivan et al., 1994; Giroux, 1991). The management of this Group has chosen to make a continuous series of disruptive changes by implementing them progressively in its system. It seems to us that the reason for choosing this approach is to experiment, test and validate these technological changes consecutively and independently, in order ultimately to improve the quality of the performance of integrated systems (Orlikowski, 2000; Gallivan et al., 1994).

\section{DISCUSSION AND CONCLUSION}

We encountered an essential difficulty, which concerns the little published research analyzing the positioning strategy and the change program of company A in France and internationally. We had to look at corporate social responsibility reports $(2019,2015)$ as well as general newspapers and specialized journal articles in order to deepen our case study.

Following the study carried out, the ETI's change program is in line with the practices adopted over the past decade (Figures 2 and 3). It seems to us that the functions involved in the site change program apply to increase the agility of the company and improve its competitive strategy (Vial, 2019; Hess et al., 2016). The management and the functions concerned are developing a strategy involving the innovation of organizational practices, in particular the expansion of sites, the computerization of processes (Figure 3). It should be noted that the adaptation of ETI A to digital variability mainly concerns activities with commercial purposes, namely the extraction, control and processing of raw materials as well as logistics (Peter el. Al., 2020; Vial, 2019; Westerman and Bonnet, 2015, Bharadwaj et al., 2013). We recall the example of the computerization of logistics, which includes the systematization and automation of the extraction and control processes of raw materials as well as those of the manufacture of natural products (Figures 2 and 3).

On the one hand, the methodological approach followed enabled us to develop an analysis of the change management of the ETI A being confronted with the variability of digital technology. The examination of its competitive strengths and its organizational practices (current and desired) highlighted the coherence of its strategic vision. Organizational practices support the realization of decisions, taken by the management of ETI A, in order to reduce the intensity of competitive forces (sections 2 and 3 ). The result of the construction of the matrix of change and its analysis are consistent with the mid-sized company's strategy (section 2)

On the other hand, this methodological approach could be used by organizations belonging to various fields (for example, hospitality, IT, information technology) or even by higher education and research institutions (for example, universities). Its motive would be to open up questions on the competitive positioning and the strategic value of information technologies, to analyze the agility of organizational practices (Vial, 2019; Hess et al., 2016; Sambamurthy et al., 2003). 
In the near future, we would like to develop two research perspectives. We hope to get in touch with the ETI A in order to interview some employees involved in this change program. We will conduct quantitative and qualitative studies to analyze the social behavior of participants (Vial, 2019; Kotter, 1997). We will study competitive positioning with an evolving vision of strategy, in the logic of resource theory. We will discuss the notion of strategic agility to complete this analysis.

\section{ACKNOWLEDGEMENT}

Translated \& edited by American Publishing Services (https://americanpublishingservices.com/).

\section{REFERENCES}

Alter, N. (2015). L'innovation ordinaire (ordinary innovation). Presses universitaires de France.

Arendt, L. (2008). Barriers to ICT adoption in SMEs: how to bridge the digital divide. Journal of Systems and Information Technology, 10(2), 93-108.

Autissier, D., \& Moutot, J.M. (2016). Méthode de conduite du changement-4e éd.: Diagnostic, Accompagnement, Performance (Change management method -4th ed.: Diagnosis, Support, Performance), Dunod.

Autissier, D., Vandangeon, I., \& Vas, A. (2014). Conduite du changement : Concepts-clés: 50 ans de pratiques issues des travaux de 25 grands auteurs (Change management: Key concepts: 50 years of practices resulting from the work of 25 great authors), Dunod.

Bharadwaj, A., El Sawy, O.A., Pavlou, P.A., \& Venkatraman, N.V. (2013). Digital business strategy: Towards a next generation of insights. MIS Quarterly, 37(2), 471-482.

Brynjolfsson, E., Renshaw, A.A., \& van Alstyne, M. (1996, Winter). The Matrix of Change: A Tool for Business Process Reengineering. Sloan Management Review.

Brynjolfsson, E., Renshaw, A.A., \& van Alstyne, M. (1997). The matrix of change. MIT Sloan Management Review, 38(2), 37.

ETI A. (2015). Corporate Social Responsibility Report. Retrieved from https://bit.ly/2G4WDEm ETI A. (2019). Corporate Social Responsibility Report. Retrieved from https://bit.ly/2XWOyKw Fitzgerald, M., Kruschwitz, N., Bonnet, D., \& Welch, M. (2014). Embracing digital technology: A new strategic imperative. MIT Sloan Management Review, 55(2).

Gallivan, M., Hofman, D., \& Orlikowski, W. (1994). Implementing radical change: Gradual versus rapid pace. Proceedings of the Fifteenth International Conference on Information Systems (pp. 325339). Vancouver, British Columbia.

Giroux, N. (1991). La gestion du changement stratégique (The management of strategic change). Gestion, 7, 19-25.

Grange, C., \& Ricoul, S. (2017). Organisations: quel est votre degré de maturité numérique? (Organizations: what is your degree of digital maturity?) Gestion, 42(1), 86-89.

Henderson, J.C., \& Venkatraman, H. (1993). Strategic alignment: Leveraging information technology for transforming organizations. IBM Systems Journal, 32(1), 472-484.

Hess, T., Matt, C., Benlian, A., \& Wiesböck, F. (2016). Options for formulating a digital transformation strategy. MIS Quarterly Executive, 15(2), 123-140.

Hopkins, M.S. (2010). The 4 ways IT is driving innovation. Interview with Erik Brynjolfsson. MIT Sloan Management Review.

Kim, W.C., \& Mauborgne, R.A. (2014). Blue ocean strategy, expanded edition: How to create uncontested market space and make the competition irrelevant. Harvard Business Review Press.

Kordahi, M. (2019). The management of change, the analysis of organizational practices in transformation. In The Proceedings of the Colloquium Development / personal-organizational change. Retrieved from http://lerass-ceric.numerev.com/actes-1-50/178-la-conduite-duchangement-1-analyse-de-pratiques- Organizations-en-transformation 
Kotter, J.P. (1997). Leading Change: Why transformation efforts fail. IEEE Engineering Management Review, 25(1), 34-40.

Mintzberg, H. (1973). Strategy-making in three modes. California Management Review, 16(2), 44-53.

Mintzberg, H., Raisinghani, D., \& Theoret, A. (1976). The structure of 'unstructured' decision processes. Administrative Science Quarterly, 21, 246-275.

Orlikowski, W.J. (2000). Using technology and constituting structures: A practice lens for studying technology in organizations. Organization Science, 11(4), 404-428

Peter, M.K., Kraft, C., \& Lindeque, J. (2020). Strategic action fields of digital transformation. Journal of Strategy and Management, 13(1), 160-180.

Porter, M.E. (1980). Industry structure and competitive strategy: Keys to profitability. Financial Analysts Journal, 36(4), 30-41.

Porter, M.E. (2008). The five competitive forces that shape strategy. Harvard Business Review, 86(1), 2540.

Sambamurthy, V., Bharadwaj, A., \& Grover, V. (2003). Shaping agility through digital options: Reconceptualizing the role of information technology in contemporary firms. MIS Quarterly, 27(2), 237-263.

Simon, H.A. (1987). Making management decisions: The role of intuition and emotion. The Academy of Management Executive, 1, 57-64.

Tapscott, D. (1996), The digital economy: Promise and peril in the age of networked intelligence (Vol. 1), McGraw-Hill, New York.

Vial, G. (2019). Understanding digital transformation: A review and a research agenda. The Journal of Strategic Information Systems, 28(2), 118-144.

Wagner, B.A., Fillis, I., \& Johansson, U. (2003). E-business and e-supply strategy in small and medium sized businesses (SMEs). Supply Chain Management: An International Journal, 8(4), 343-354.

Westerman, G., \& Bonnet, D. (2015). Revamping your business through digital transformation. MIT Sloan Management Review, 56(3), 10.

Westerman, G., Calméjane, C., Bonnet, D., Ferraris, P., \& McAfee, A. (2011). Digital Transformation: A roadmap for billion-dollar organizations. MIT Center for Digital Business and Capgemini Consulting, 1, 1-68. 